\title{
Chromosome 22q11 deletion presenting as the Potter sequence
}

\author{
Koenraad Devriendt, Philippe Moerman, Dominique Van Schoubroeck, \\ Kamiel Vandenberghe, Jean-Pierre Fryns
}

\begin{abstract}
A female fetus with the Potter sequence, caused by unilateral renal agenesis and contralateral multicystic renal dysplasia, was found to have a submicroscopic deletion in chromosome 22q11. The only associated anomaly was agenesis of the uterus and oviducts (Von Mayer-RokitanskyKüster anomaly). The deletion was inherited from the father, who presented the typical velocardiofacial syndrome phenotype, but no urological anomalies. This observation further extends the clinical spectrum associated with a deletion in 22q11.

( $¥$ Med Genet 1997;34:423-425)
\end{abstract}

Keywords: chromosome 22q11; velocardiofacial syndrome; kidney; Potter sequence

Severe bilateral renal insufficiency during prenatal life can lead to a decreased amount of amniotic fluid, resulting in a number of fetal deformations recognisable as the Potter sequence. ${ }^{1}$ Aetiologically, this is a heterogeneous condition, with known genetic causes, such as chromosomal aberrations or mendelian disorders, and teratogenic factors. ${ }^{2}$ However, in most instances, the cause is not known. Here, we report a fetus with the typical Potter sequence caused by unilateral renal agenesis and contralateral multicystic renal dysplasia and carrying a del(22q11).

Centre for Human

Genetics, University

Hospital Leuven,

Herestraat 49, B-300

Leuven, Belgium

K Devriendt

J-P Fryns

Department of

Pathology 1, University

Hospital Leuven,

Belgium

P Moerman

Department of

Obstetrics and

Gynecology, University

Hospital Leuven,

Belgium

D Van Schoubroeck

$\mathrm{K}$ Vandenberghe

Correspondence to:

Dr Devriendt.

Received 10 September 1996 Revised version accepted for publication 4 December

1996 other associated anomalies were noted. Chorionic villus biopsy was performed and the karyotype was normal after $\mathrm{G}$ and $\mathrm{T}$ banding. The pregnancy was aborted and external examination of the fetus showed retrognathia, anteverted ears, flexion and endorotation of both feet, and overlapping fourth, third, and second fingers of the left hand. No other deformations were noted. Internal examination confirmed the presence of a left multicystic kidney with a normal appearance of the left ureter. The right kidney and ureter were absent. Both adrenal glands were normal. Both ovaries appeared elongated. The uterus, oviducts (except for a small part of the right oviduct), and proximal portion of the vagina were absent (von Mayer-Rokitansky-Küster or MRK anomaly). There was a connection between the vulva and bladder. No other internal anomalies were present; more specifically, no cardiovascular malformations were observed. Histological examination of the left kidney confirmed the presence of multicystic dysplasia, with only very few normal nephrons and glomeruli.

The parents were referred for genetic counselling. Family history was negative with regard to urological malformations. Both parents have borderline intelligence. The father had learning difficulties. He was noted to have marked hypernasal speech, for which he received speech therapy during childhood. His facial features were typical of velocardiofacial syndrome (VCFS), with a high nasal bridge, mild hypertelorism, narrow palpebral fissures, and a small mouth and chin. Renal and cardiac ultrasound examinations were normal.

High resolution karyotype in the father and mother were normal. In the father, a deletion in chromosome 22q11 was detected by means of FISH, using probe DO832. ${ }^{3}$

FISH was performed on 164 interphase chorionic villus cell nuclei using probe DO832. One signal was detected in 120 (73\%), two signals in two (1\%), and 42 nuclei $(25 \%)$ could not be analysed or produced no signal. Only a single analysable metaphase was present, showing a signal in only one of the chromosomes 22 . Two control samples from fetuses with a normal karyotype, 100 nuclei each, were analysed in parallel and showed a single signal in $10 \%$ and $17 \%$, two signals in $60 \%$ and $66 \%$, and no signal in $30 \%$ and $17 \%$.

Ten additional, unrelated cases of Potter syndrome, caused by an isolated, severe urological malformation, were studied retrospectively by means of FISH, using probe D0832 on metaphase spreads from cultured fibroblasts. In none of these was a $\operatorname{del}(22 \mathrm{q} 11)$ detectable.

\section{Discussion}

The index patient in this report had the Potter sequence, caused by unilateral renal agenesis and contralateral cystic renal dysplasia. The only associated malformation was the absence of the uterus and upper portion of the vagina, a condition known as the Von MayerRokitansky-Küster (MRK) anomaly. The facial dysmorphism was compatible with deformations caused by oligohydramnios. After the diagnosis of VCFS in the father, a submicroscopic deletion in chromosome $22 \mathrm{q} 11$ was found in this fetus.

The clinical expression of a submicroscopic deletion in chromosome $22 \mathrm{q} 11$ is highly 
variable. Most patients present with a conotruncal heart malformation or a velopharyngeal defect, usually associated with a distinct craniofacial dysmorphism and learning difficulties. ${ }^{4}$ Several additional features caused by an abnormal morphogenesis have been described, such as limb defects and brain malformations. ${ }^{5-7}$ Urological malformations are increasingly being recognised in patients with a del(22q11) and include renal agenesis, ${ }^{8}$ multicystic renal dysplasia (MRD), ${ }^{10}$ vesicoureteral reflux (VUR) ${ }^{4}$ ectopic kidney, ${ }^{11}$ and vesicoureteral junction obstruction. ${ }^{12}$ Renal tract malformations were also found in $6 / 10$ VCFS patients by Olney et al..$^{13}$ The frequent occurrence of urological malformations in these syndromes strongly suggests that this is a variable manifestation of a $\operatorname{del}(22 q 11)$. Even though we cannot exclude the possibility of two unrelated disorders, the patient reported here illustrates that, in VCFS, the renal malformations can lead to the Potter sequence and can completely dominate the clinical phenotype. Certainly, additional studies to confirm the present observation are needed.

No other malformations typical of VCFS were present, such as cleft palate or heart defect. The retrognathia and slightly dysmorphic features could represent features of VCFS, but could equally be attributed to the oligohydramnios. If the father had not been diagnosed with VCFS, the diagnosis in the fetus would not have been suspected. We therefore propose that in all instances of Potter sequence, a deletion in chromosome 22q11 should be excluded, even in the absence of other features of VCFS. We have retrospectively investigated 10 other cases of Potter sequence, and no other patient with a $\operatorname{del}(22 \mathrm{q} 11)$ was found.

In the present patient, there was an associated MRK anomaly. Müllerian duct anomalies are frequently found in association with urological malformations suggesting that the Müllerian and Wolffian ducts belong to the same developmental field. ${ }^{14-16}$ It can be expected that uterine malformations will be found with greater frequency in females with the VCFS, and possibly also anomalies of the vas deferens in males with VCFS.

The different urological malformations in VCFS probably result from abnormal development of the ureter bud. ${ }^{17}$ In the present patient, a multicystic and dysplastic kidney was found on one side, with intact ureter, suggesting that this was caused by an early and total pelviureteral junction obstruction (PUJO). Renal agenesis, as found on the contralateral side in this patient, can result from the lack of induction of the metanephric blastema by the ureter bud. Alternatively, renal agenesis can also result from the regression of a multicystic kidney. ${ }^{18}$ However, an intrinsic developmental error in the metanephrogenic blastema cannot be excluded with certainty.

VCFS is caused by a submicroscopic deletion in chromosome 22q11. Even though the microdeletions in $22 \mathrm{q} 11$ include many genes, the cardinal features of VCFS, cleft palate, conotruncal heart malformation, and distinct facial features, are thought to result from a haploinsufficiency for a single gene, as was suggested by the DiGeorge/VCFS phenotype in a patient with a balanced reciprocal translocation involving $22 \mathrm{q} 11 .^{19}$ The pathogenesis is thought to be related to an abnormal function of the cranial neural crest. ${ }^{20} \mathrm{~A}$ role for neural crest cells in the development of Wolffian and Müllerian structures has so far not been found. It therefore cannot be excluded that the urological malformations are caused by haploinsufficiency for another gene within the critical deletion region in $22 \mathrm{q} 11$. Certain variable features of VCFS can be attributed to other genes, such as Bernard-Soulier syndrome (the GPIb beta gene) ${ }^{21}$ or the increased succeptibility to psychiatric disorders which might be related to the deletion of the COMT gene. $^{22}$ On the other hand, renal anomalies (including agenesis and cystic dysplasia) have also been found in patients with DiGeorge syndrome caused by maternal diabetes and deletions of chromosome 10 p. $^{23}{ }^{24}$ If these uropathies were also related to an abnormal ureteral bud development, then this could indicate that the Wolffian and Müllerian ducts may belong to the same developmental field as derivatives from the third and fourth pharyngeal pouches. The urological and Müllerian malformations could thus also result from a pleiotropic effect of the same gene in 22q11 that is responsible for the conotruncal heart malformations and thymic and parathyroid hypoplasia.

In most VCFS patients, the 22q11 deletion spans approximately $2 \mathrm{Mb}^{25}$ No correlation between the length of the deletion and severity of the disease has been found and also, in the present family, the father and child, almost certainly sharing the same deletion, were discordant for the presence of renal anomalies. This suggests that, as for the cardiac malformations, other factors are involved in the expression of these malformations, including genetic and environmental factors and probably chance as well. ${ }^{26}$

We thank Dr P Scambler for his generous gift of the probe DO832.

1 Potter EL. Facial characteristics of children with bilateral renal agenesis. Am f Obstet Gynecol 1946;41:855-88.

2 Curry CJR, Jensen K, Holland J, Miller L, Hall BD. The Potter sequence: a clinical analysis of 80 cases. $\mathrm{Am} \mathfrak{F} \mathrm{Med}$ Genet 1984;19:679-702.

3 Wadey R, Daw S, Wickremasinghe A, et al. Isolation of a new marker and conserved sequences close to the DiGeorge syndrome marker HP500 (D22S134). F Med Genet 1993;30:818-21.

4 Lipson AH, Yuille D, Angel M, et al. Velocardiofacial (Shprintzen) syndrome: an important syndrome for the dysmorphologist to recognise. $\mathcal{F}$ Med Genet 1991;28:596604.

5 Cormier-Diare V, Iserin L, Théophile D, et al. Upper limb malformations in DiGeorge syndrome. Am $\mathcal{F}$ Med Genet 1995;56:39-41.

6 Mitnick RJ, Bello JA, Shprintzen RJ. Brain anomalies in velo-cardio-facial syndrome. Am 7 Med Genet 1994;54:1006.

7 Devriendt K, Van Thienen MN, Swillen A, Fryns JP. Cerebellar hypoplasia in a patient with velo-cardio-facial Cerebellar hypoplasia in a patient with velo-card

8 Wilson DI, Burn J, Scambler P, Goodship L. DiGeorge Wilson DI, Burn J, Scambler P, Goodship L. DiGeorge
syndrome: part of CATCH 22. f Med Genet 1993;30:852-

9 Driscoll DA, Budarf ML, Emanuel BS. A genetic etiology for DiGeorge syndrome: consistent deletions and microdeletions of 22q11. Am ₹ Hum Genet 1992;50:924-33.

10 Palacios J, Gamallo C, Garcia M, Rodriguez JI. Decrease in thyrocalcitonin-containing cells and analysis of other 
congenital anomalies in 11 patients with DiGeorge anomaly. Am $\mathcal{F}$ Med Genet 1993;46:641-6.

11 Meinecke P, Beemer FA, Schinzel A, Kushnick T. The velocardio-facial (Shprintzen) syndrome: clinical variability in eight patients. Eur $\mathcal{F}$ Pediatr 1986;145:539-44.

12 Devriendt K, Swillen A, Proesmans W, Gewillig M, Fryns JP. Renal and urological tract malformations caused by 22q11 deletion. 7 Med Genet 1996;33:349.

13 Olney AH, MacDonald MR, Schaefer GB, Sanger WG Atypical clinical presentations of patients with 22q microdeletions. 3rd foint Clinical Genetics Meeting, San microdeletions. 3rd

14 Roodhooft AM, Birnholz JC, Holmes LB. Familial nature of congenital absence and severe dysgenesis of both kidneys. congenital absence and severe dysgenesis of both kidneys.

5 Biedel CW, Pagon RA, Zapata JO. Müllerian anomalies and renal agenesis: autosomal dominant urogenital adysplasia. f Pediatr 1984;104:861-4.

16 Opitz JM. Editorial comment: vaginal atresia (von MayerRokitansky-Küster or MRK anomaly) in hereditary renal adysplasia (HRA). Am $\mathcal{F}$ Med Genet 1987;26:873-6.

17 Devriendt K, Fryns JP. A genetic locus on chromosome $6 p$ for multicystic renal dysplasia, pelvi-ureteral junction stenosis and vesicoureteral reflux. $\mathrm{Am} 7 \mathrm{Med}$ Genet 1995;59:396-7.

18 Mesrobian HGJ, Rushton HG, Bulas D. Unilateral renal agenesis may result from in utero regression of multicystic renal dysplasia. 7 Urol 1993;150:793-4.
19 Budarf ML, Collins J, Gong W, et al. Cloning a balanced translocation associated with DiGeorge syndrome and identification of a disrupted candidate gene. Nat Genet 1995;10:269-77.

20 Bockman DE, Kirby ML. Dependence of thymus development on derivatives of the neural crest. Science 1984;223: 498-500.

21 Budarf ML, Konkle BA, Ludlow LB, et al. Identification of a patient with Bernard-Soulier syndrome and a deletion in a patient with Bernard-Soulier syndrome and a deletion in 22q11.2. Hum Mol Genet 1995;4:763-6.

22 Dunham I, Collins J, Wadey R, Scambler P. Possible role for COMT in psychosis associated with velo-cardio-facial syndrome. Lancet 1992;340:1361.

23 Wilson TA, Blethen SL, Vallone A, et al. DiGeorge anomaly with renal agenesis in infants of mothers with diabetes. $\mathrm{Am}$ 7 Med Genet 1993;47:1078-82.

24 Schuffenhauer S, Seidel H, Oechsler H, et al. DiGeorge syndrome and partial monosomy 10p: case report and review. Ann Genet (Paris) 1995;35:162-7.

25 Lindsay EA, Greenberg F, Shaffer LG, et al. Submicroscopic deletions at 22q11.2: variability of the clinical picture and delineation of a commonly deleted region. $\mathrm{Am}$ f Med Genet 1995;56:191-7.

26 Goodship J, Cross I, Scambler P, Burn J. Monozygotic twins with chromosome 22q11 deletion and discordant phenotype. F Med Genet 1995;32:746-8. 